\title{
Habitação como patrimônio: a preservação dos conjuntos residenciais modernos
}

Flávia Brito do Nascimento*

\section{Resumo:}

Este trabalho visa problematizar a preservação dos conjuntos residenciais empreendidos entre 1930 e 1964 em todo o país pelos Institutos de Aposentadoria e Pensões, pelo Departamento de Habitação Popular e pela Fundação da Casa Popular. Tais conjuntos residenciais são exemplares importantes da história da arquitetura moderna brasileira e têm sua salvaguarda seriamente ameaçada. Integrando as agendas da preservação e da habitação social, propomos estudá-los e entendê-los como patrimônio cultural, objetivando reunir esforços para definir parâmetros conceituais e traçar estratégias de gestão e de preservação. Pretendemos tomar parte do debate sobre a preservação da arquitetura e do urbanismo modernos a partir do tópico da habitação social, enfrentando as questões da atribuição de valor e da atualidade e/ou obsolescência das propostas do morar moderno.

Palavras-chave: Conjuntos Residenciais. Arquitetura moderna. Preservação.

Housing as a cultural heritage: the preservation of modern housing blocks

\begin{abstract}
:
This article aims at discussing the preservation of housing blocks built between 1930 and 1964 all over Brazil by the Institutes of Social Security, by the Department of Social Housing and by the Foundation of the Social House. Those housing blocks are important examples of the history of Brazilian modern architecture and their keeping is seriously threatened. By integrating preservation and social housing agendas we propose to study them and understand them as cultural heritage and to gather forces in order to define conceptual parameters and to outline preservation and management strategies. We intend to take part in the debate on the preservation of modern architecture and urbanism from the point of view of social housing. We will
\end{abstract}


face the problem of valuation and the problem of contemporariness and/or obsolescence of modern housing proposals.

Key-words: Housing blocks. Modern architecture. Preservation.

Em 2004 o governo alemão organizou uma listagem para encaminhar à Unesco de seis conjuntos residenciais para serem reconhecidos patrimônio da humanidade. Os conjuntos, construídos entre 1913 e 1930, e de autoria de arquitetos como Bruno Taut, Walter Gropius e Hans Scharoun, eram parte do projeto de ação de Martin Wagner à frente da Secretaria de Habitação de Berlim (MELLO, 2004).

A iniciativa, inédita se analisarmos os bens imóveis que integram a listagem da Unesco (1), significa a possibilidade de oficialmente serem chamadas de patrimônio mundial edificações que até pouco tempo eram vistas com reservas no campo da preservação, sendo desconsiderados seus valores históricos ou estéticos. O pedido de reconhecimento confere importância a uma das facetas fundamentais e polêmicas do movimento moderno: a transformação da sociedade por meio das mudanças espaciais.

A construção em massa dos grandes conjuntos habitacionais do pós-guerra foi duramente questionada a partir dos anos 1950 por grupos como o Team X e os Situacionistas. O corpo teórico que formulou as críticas avolumou-se com os movimentos culturalistas e pós-modernos dos anos 1960 e 1970. Jane Jacobs, Robert Venturi e Aldo Rossi acusavam o modernismo de ser indiferente às tradições da própria arquitetura e dos contextos particulares. Ou seja, ao ignorar as especificidades locais, criava espaços pouco relacionados às práticas cotidianas de onde se instalava (JACQUES, 2004).

A morte do movimento moderno chegou a ser anunciada por Charles Jencks com a demolição de nada menos de um conjunto residencial, símbolo da incapacidade do moderno de produzir lugares habitáveis. Vale reproduzir o já muitas vezes citado Charles Jencks: 


\begin{abstract}
"Felizmente, podemos datar a morte da arquitetura moderna em um momento preciso no tempo. À diferença da morte jurídica de uma pessoa, que vem se tornando um complexo assunto de ondas cerebrais versus batimentos cardíacos, a arquitetura moderna extinguiuse em surdina. [...] A arquitetura moderna morreu em St. Louis, Missouri, no dia 15 de julho de 1972, às 3:32 p.m. (ou por aí), quando o infame projeto Pruitt-Igoe, ou melhor, vários de seus blocos, receberam o coup de grâce com dinamite." (JENCKS, 1978, p.9, tradução nossa).
\end{abstract}

Curiosamente, as críticas endereçadas ao movimento moderno integraram um conjunto maior de importantes mudanças no campo da preservação, as quais tornaram os objetos mais diversificados e menos pautados em critérios estéticos. Um processo de valorização da herança material do movimento moderno tem lugar a partir do arrefecimento dos embates dos anos 1960 e 1970 e da ampliação cada vez maior do que é considerado patrimônio a salvaguardar. No caso brasileiro, o conceito exclusivamente histórico ou estético que havia norteado as ações do Iphan - Instituto do Patrimônio Histórico e Artístico Nacional entre 1937 e o final dos anos 1960 (período da gestão de Rodrigo Melo Franco de Andrade), foi substituído por uma noção maior que inclui a história como apenas uma das possibilidades de interpretação da cultura (ROCHA-PEIXOTO, 1990). E passou-se à preservação de um leque mais aberto de bens com significação diversificada, na qual os exemplares da arquitetura e do urbanismo moderno poderiam ter lugar. Citando Françoise Choay:

"[...] um mundo de edifícios modestos, nem memoriais, nem prestigiosos, reconhecidos e valorizados por disciplinas novas como a etnologia rural e urbana, a história das técnicas, a arqueologia medieval, foram integrados ao corpus patrimonial. Contudo, o aporte mais considerável de novos tipos se deve à transposição do muro da industrialização e à anexação, pela prática conservatória de edifícios da segunda metade do século XIX e do século XX." (CHOAY, 2001, p.209).

No Brasil, desde o final dos anos 1980 muito tem sido dito acerca da arquitetura e do urbanismo modernos. Fomentada pela valorização da pesquisa e do conhecimento teórico no campo da arquitetura, pelo conseqüente crescimento dos programas de pós-graduação em todo o País, e pelo aumento dos fóruns de debates 
especializados como o Docomomo (2), uma geração de pesquisadores organizouse, estabelecendo novos parâmetros para a historiografia do movimento moderno. A produção dita canônica foi sucessivamente questionada. Colocou-se em perspectiva crítica a narrativa que teve por mito fundador a revelação da "verdadeira" arquitetura nacional, supostamente estabelecida como "missão" a partir dos eventos na ENBA e da vinda de Le Corbusier como consultor do MES (3) (CAVALCANTI, 1987).

Novas abordagens metodológicas oriundas da história cultural diversificaram as fontes e os objetos. O entendimento dos processos da arquitetura e do urbanismo brasileiro ficou menos linear: nomes consagrados foram revisitados e revelaram facetas inesperadas e surpreendentes. Inúmeros personagens e obras antes obscurecidos passaram a integrar as narrativas de constituição da disciplina no Brasil do século 20 (4).

Mesmo crescendo a atribuição de valor às obras, na medida em que aumentou o conhecimento da arquitetura e do urbanismo modernos, e mesmo as instituições de salvaguarda valorizando a diversidade cultural, não se consubstanciaram ações efetivas e de maior alcance de preservação de seus exemplares. Em instância federal, estão legalmente protegidos alguns bens imóveis, mormente ícones da arquitetura brasileira. A Igreja da Pampulha foi a primeira obra moderna tombada pelo Iphan, protegida em 1947, ainda em construção, de modo a assegurar sua execução conforme o projeto de Oscar Niemeyer. No ano seguinte, foi a vez do Ministério da Educação e Saúde (Palácio Gustavo Capanema), em si um testemunho do triunfo da assim chamada "primeira geração moderna". A Estação de Hidroaviões, de Attílio Correia Lima e Renato Soeiro, o Parque do Flamengo, de Affonso Eduardo Reidy, e a Catedral de Brasília, foram tombados ainda na presença de Lucio Costa no Patrimônio. (LUCENA, 2006). Nos anos 1980, na esteira dos novos paradigmas de preservação, ocorreram pedidos de salvaguarda, ainda que, mormente, visando as obras emblemáticas, tais como a ABI dos Irmãos Roberto, e o Parque Guinle de Lucio Costa, ambos tombados em nível federal.

Pioneiramente, nova perspectiva de valorização do moderno foi estruturada para o tombamento da cidade de Cataguases, MG, realizado pelo Iphan, e cujo processo foi instruído nos anos 1980, e aprovado em 1995, tendo como relator ítalo 
Campofiorito. Cataguases foi o berço de dois movimentos centrais no modernismo no País: o cinema de Humberto Mauro e a Revista Verde. Congregou em seu espaço urbano a estética moderna, emulada da aura, do espírito de vanguarda dos intelectuais. O tombamento da cidade buscou não destacar exclusivamente os elementos isolados, como as obras de Oscar Niemeyer ou de Francisco Bolonha, mas a diversidade dos elementos construtivos, o ambiente do espírito moderno, abarcando cerca de 60 quadras no centro da cidade. Área esta, ocupada por edificações modestas e anônimas, denominadas pelo arquiteto Antônio Luiz Dias de Andrade de "arquitetura vernacular moderna" (SANTOS; LAGE, 2005).

Mesmo com o moderno entrando na agenda da conservação de bens imóveis, Cataguases permanece singular. Genericamente, o viés é tradicional e insuficiente: são oficialmente preservadas para o futuro, em nível federal, poucas obras, como Grande Hotel e Parque Guinle, de Lucio Costa, e as Casas Modernistas, de Warchavchik.

Nas diferentes estâncias estaduais e municipais a realidade vem se transformando. Em julho de 2006, a Prefeitura da Cidade do Rio de Janeiro tombou doze exemplares "representativos do patrimônio cultural e arquitetônico do Movimento Moderno na Cidade do Rio de Janeiro". A lista inclui obras como a Residência Carmen Portinho e o Albergue da Boa Vontade, de Affonso E. Reidy, o Edifício Marquês do Herval e a Sede do IRB, dos Irmãos Roberto, e a Residência Walter Moreira Salles, de Olavo Redig de Campos. (D.O. Rio 12.7.2006). No caso de São Paulo, o Programa Toledo-Lemos, contratado em 1974 para servir de base aos trabalhos de levantamento e seleção de imóveis e conjuntos arquitetônicos representativos para preservação, listou alguns importantes edifícios modernos. Tornado lei em 1075 pela prefeitura, estabeleceu zonas especiais de proteção, as Z8-200, elencando obras como o Edifício Esther de Vital Brasil (ATIQUE, 2003).

Se tradicionalmente no campo preservação do patrimônio cultural no País poucas vezes se tratou do moderno, menos atenção foi dada à habitação de interesse social. Nos anos 1980, em virtude da diversificação temática, algumas vilas operárias foram estudadas e preservadas. É o caso de duas vilas operárias na cidade de Petrópolis, RJ, tombadas pelo Iphan nos anos 1980, não por serem 
significativas para a história da arquitetura, mas por representarem a ocupação urbana e a história da cidade.

Nas vezes em que se falou em habitação social aliada à preservação, o viés ocorreu pela lógica da ocupação dos espaços vazios nos centros urbanos, por meio da moradia. Dito de outro modo, a habitação como solução eficaz à gentrificação e à museificação das cidades (5).

A essa perspectiva, parece ser interessante somar-se a da própria habitação social na qualidade de patrimônio, enfrentando, deste modo, os desafios dos usos, transformações e reconceituações dos moradores atuais.

Os conjuntos residenciais estão obscurecidos pelas práticas de patrimônio calcadas na estética, no privilégio às áreas centrais das cidades e na excepcionalidade das obras, e, portanto, ameaçando sua permanência e seu papel nas cidades contemporâneas. Dialogando com os defensores do patrimônio industrial e do patrimônio moderno, acreditamos ser fundamental entender os conjuntos como herança arquitetônica e urbanística do processo de industrialização, e entender tais estruturas como parte da paisagem de nossas cidades e como página importante da história da habitação social no Brasil.

A historiografia da arquitetura nacional até muito recentemente pouco havia falado da produção de habitação social. Os autores consagrados como Bruand (1991) e Mindlin (1999) referem-se quase exclusivamente aos projetos de maior repercussão, como o Conjunto Residencial Pedregulho, e não os vêem como pertencentes a uma concepção maior de habitação e interligados ao projeto nacional de modernização. Novas perspectivas (6) trouxeram à luz os empreendimentos habitacionais brasileiros, relacionando-os às reflexões e à produção arquitetônica moderna, já que, historicamente, encontravam-se alijados desta posição.

Os conjuntos residenciais construídos no Brasil entre 1930 e 1964 são extremamente diversos em tipologia. Edifícios em altura, isolados no terreno, coexistem com as pequenas casas unifamiliares com quintal ou com renques de sobrados enfileirados. A multiplicidade de soluções vindas das pranchetas dos 
arquitetos (os quais mesclavam a prática privada ao trabalho nas repartições públicas) é reveladora de sua diversidade conceitual. As soluções não eram únicas e sequer filiavam-se a uma corrente teórica: as proposições do CIAM, o ideário corbusiano, as cidades-jardim ou o urbanismo viário americano estavam presentes nos conjuntos e eram reapropriadas e recriadas de acordo com as possibilidades e limitações locais. Foram cerca de 600 conjuntos construídos pelos diversos institutos e departamentos em todo território nacional, dos quais podemos citar: Realengo (RJ) e Vila Guiomar (SP), ambos do arquiteto Carlos Frederico Ferreira; Penha (RJ) e Anchieta (SP), de autoria dos Irmãos Roberto; Paquetá (RJ), de Francisco Bolonha; Deodoro (RJ), de Flavio Marinho Rego; Casa da Bancária (RJ), arquiteto Carlos Leão; e Pedregulho (RJ), de Affonso E. Reidy (SAMPAIO; BONDUKI, 1998).

O início da construção desses conjuntos remonta ao governo Vargas, ficando a cargo dos Institutos de Aposentadorias e Pensões - IAPs, criados para as diferentes categorias profissionais, como um desdobramento das Caixas de Aposentadorias e Pensões de 1923. A partir do Estado Novo, surgem condições para a atuação efetiva dos IAPs no campo habitacional, com o Decreto $\mathrm{n}^{\circ} 1789$, que autorizava os Institutos a criar carteiras prediais, podendo destinar até metade de suas reservas para o financiamento de construções habitacionais, com redução das taxas de juros e ampliação dos prazos de pagamento.

A produção habitacional e a arquitetura moderna estiveram lado a lado e foram centrais no processo de constituição do trabalhador estadonovista. Com a Revolução de 30, a habitação será entendida como um dos fortes instrumentos de mudança. Dois princípios marcarão a produção de moradia, a partir de então. A habitação deveria ser: 1. transformadora do "status" do trabalhador, de cunho educativo; 2. financiada e produzida pelo Estado (NASCIMENTO, 2004).

Apesar de sua importância histórica e da sua representatividade nas cidades brasileiras, é grande a carga negativa que se construiu a seu respeito. Mesmo com os esforços de valorização do modernismo, a estigmatização e o preconceito persistem. Muitos estão degradados e foram transformados ou reutilizados, sendo a imagem do fracasso do ideal moderno, da inadequação das propostas às necessidades de habitar brasileiras. O estabelecimento de novos modos de morar 
vinculados à criação, a partir do Estado Novo, do novo homem brasileiro, é o pivô das críticas, as quais fragilizam e questionam sua própria existência e, logo, sua salvaguarda.

Mesmo crescendo o conhecimento acerca do movimento moderno, ainda se vêem os conjuntos produzidos nesse período como inadequados, feios, que devem ser escondidos. As críticas endereçadas aos conjuntos residenciais, ao afirmarem a sua inadequação, redundaram retirar seus significados históricos e/ou estéticos impeditivos de ações práticas no campo da habitação social que os coloquem hoje em posição de solução aos problemas da moradia.

A problemática da arquitetura moderna enquanto patrimônio, a qual atinge diretamente os conjuntos residenciais aqui discutidos, está envolvida nos dilemas da história da preservação no Brasil que teve como pensadores e articuladores intelectuais do modernismo, como Rodrigo Melo Franco de Andrade, Lucio Costa, Carlos Drummond de Andrade, Carlos Leão e Alcides da Rocha Miranda.

Acreditamos que não se atribui propriamente valor aos bens imóveis do período moderno em decorrência dos problemas históricos do patrimônio no País. A identidade patrimonial está profundamente atrelada às principais figuras do modernismo, o que dificulta assumi-los como passado.

No contexto internacional, a arquitetura moderna tornou-se passado em meados dos anos 1960, embora seu processo de historicização já fosse sentido no final dos anos 1950 e início dos anos 1960, por meio de ações pontuais para o salvamento de seu legado e de estudos de caráter histórico, como é o caso do livro de Leonardo Benevolo "História da Arquitetura Moderna". É nesse período que se preservam a Weissenhof Siedlung, a Robie House e a Ville Savoye, mobilizando inclusive arquitetos vinculados ao movimento moderno. Nos anos 1980, o moderno entra na pauta da preservação e se organizam em todo mundo fóruns de debates, visando traçar prioridades e estratégias (CARVALHO, 2006, p.7-27).

No caso brasileiro, por razões decorrentes do processo histórico, o patrimônio está marcado pelas concepções de identidade nacional ancoradas no período colonial, 
cuja essência máxima é representada em cidades como Ouro Preto, Paraty e Olinda. Para Lucio Costa, chefe do Departamento de Estudos de Tombamento do IPHAN por cerca de 30 anos, a arquitetura daria concretude à nação (CHUVA, 2003).

Como estudou Cecília Fonseca (1997), o patrimônio como expressão da nacionalidade foi elaborado, a partir da Revolução Francesa, no projeto de construção da identidade nacional, e passou a servir à consolidação dos Estados Nacionais. Ao patrimônio foram atribuídas funções simbólicas como reforçar a cidadania, identificar os bens representativos da nação, proteger o patrimônio comum e reforçar a coesão nacional. Os bens patrimoniais deviam ser provas documentais das versões da história nacional, cuja conservação é justificada por seu alcance pedagógico.

Os temas do patrimônio no Brasil tornam-se politicamente relevantes a partir da década de 1920. Intelectuais modernistas, baseados em concepções de arte, história, tradição e nação criam um conceito de patrimônio que se tornou hegemônico no Brasil, assumido pelo Iphan - Instituto do Patrimônio Histórico e Artístico Nacional, implantado em 1937 com o objetivo de proteger as obras de arte e a história do País. O período que vai da fundação até meados dos anos 1960 ficou marcado pela valorização quase exclusiva das expressões do barroco. $\mathrm{O}$ caráter estético, sob cânones modernistas, norteou grande parte das ações de preservação, nas quais os valores históricos foram desconsiderados (CAMPOFIORITO, 1985).

A primeira metade dos anos 1960 trouxe grandes transformações políticas e a politização da atividade cultural. As Ligas Camponesas e os CPCs (Centro Populares de Cultura) implicavam numa percepção mais dogmática de arte e de cultura popular. Nesse contexto, assiste-se a um profundo desgaste do modelo implantado nas primeiras décadas de institucionalização do Patrimônio. A desconsideração dos valores históricos nas práticas de preservação, o olhar exclusivo aos monumentos, foram postos em cheque por não mais darem conta dos novos "adversários": o crescimento urbano e a especulação imobiliária. Diversificamse os campos de atuação e a noção dos "esquecidos" pela história oficial é incorporada aos órgãos de patrimônio. Agregando-se os conceitos da etnografia e 
da antropologia, legitimou-se o valor cultural das expressões artísticas, sendo, por conseqüência, ampliadas as noções de patrimônio e a elas incorporadas a noção dos direitos culturais (FONSECA, 1997). Citando Aloísio Magalhães:

"[...] o que se percebe é que o conceito de bem cultural extrapola a visão elitista, de 'o belo e o velho', e entra numa faixa mais importante da compreensão como manifestação geral de uma cultura. O gesto, o hábito, a maneira de ser da nossa comunidade se constituem no nosso patrimônio cultural." (MAGALHÃES, 1985, p. 63).

No âmbito dessas reflexões feitas pelo ex-presidente do Iphan, o conceito de patrimônio ampliou-se na década de 1970. Este se despe do valor simbólico nacional, passando a servir de apoio à luta pela manutenção de um meio ambiente urbano menos adensado. As preocupações recaem sobre a manutenção da escala urbana e à idéia de ambiência, a qual permite a inclusão de outros estilos, anteriormente rejeitados, ao repertório da preservação, revogando-se a primazia de um estilo único na compreensão do patrimônio cultural (MOTTA, 2000).

$\mathrm{Na}$ década de 1980 novas pressões de crescimento recaem sobre os centros históricos. Abre-se a possibilidade de valoração dos sítios urbanos como documentos, isto é, em virtude do que representam como vestígios do processo de ocupação do território. Rompe-se com a perspectiva estritamente visual, fachadística ou das características estilísticas. O que importa são os significados contidos nas formas da materialidade da cidade, construídos pelas comunidades que nela habitam. É clara a proposição de Ítalo Campofiorito feita em 1984 (7):

\footnotetext{
"1 - a diversidade ilimitada do bem cultural deve ser reconhecida e louvada; 2 - o patrimônio não constitui um acervo de coisas passadas, mas, ao contrário, é parte viva da poética do povo e dos artistas; 3 - as populações com sua sabedoria local, devem participar ativamente da defesa de um patrimônio que é seu." (CAMPOFIORITO, 1984, p.23).
}

Tais elaborações do patrimônio enquanto documento, desenvolvidas durante toda a década de 1980 pelos diversos órgãos de preservação no Brasil, foram suplantadas ou, ao menos, obscurecidas, nos anos 1990. As intervenções recentes em cidades históricas como Salvador e Rio de Janeiro (em particular na Praça 15) visaram o consumo visual, envolvendo seu enobrecimento e seu uso como produto. A 
apropriação cenográfica dos espaços urbanos desconsiderou as práticas de preservação calcadas na historiografia da cultura, as quais criaram "as bases para o reconhecimento da história de cada localidade, independentemente do julgamento de suas características arquitetônicas, visuais, estéticas ou estilísticas." (MOTTA, 2000, p.259).

Como mostra Françoise Choay (2001), tornaram-se comuns reconstituições históricas ou fantasiosas visando apresentar o monumento como um espetáculo, ou seja, animá-lo culturalmente. Tira-se o edifício da sua própria inércia, para torná-lo mais consumível. Houve, portanto, uma drástica mudança de perspectiva, na qual os bens culturais aproximam-se da idéia de mercadoria e são associados ao poder e ao status. Assiste-se à estetização da arquitetura e do patrimônio, próprio ao consumo.

Este é o aspecto que atinge particularmente a preservação da arquitetura moderna e os conjuntos residenciais. Fáceis são as argumentações que os tacham de terem pouco ou nenhum apelo estético. Entendemos que as práticas de patrimônio são resultado de uma seleção diante de objetivos e projetos específicos. Nunca são atos desinteressados, dependem do ponto de vista da seleção, do significado que se deseja atribuir (CHUVA, 1998; GONÇALVES, 2002).

Pensar em preservar a cultura material do século 20, portanto, implica construir argumentações que as signifiquem, atribuam valor, confiram importância e assegurem a perpetuação às gerações futuras. Alguns são os obstáculos que podemos problematizar: a fragilidade e a vulnerabilidade dos materiais e de seus aspectos construtivos; os pouco conhecidos processos de degradação; a perda da função original e a falta de distanciamento histórico (CARVALHO, 2006).

A perspectiva histórica constrói uma das grandes questões teóricas no que se refere aos conjuntos residenciais. Em que medida podemos considerá-lo passado? Um dos pontos nodais é o aparente paradoxo de se preservar uma arquitetura postulada para romper com as tradições. Esta é, contudo, uma construção parcial do problema. Tratá-los como patrimônio, não significa decretá-los ultrapassados. Significa, ao contrário, entendê-los como parte viva e importante de nossa cultura 
contemporânea e enfrentar o desafio de compreender a relação entre os conceitos originais que os nortearam e sua utilização no presente.

É possível verificar o valor intrínseco da obra modernista e até mesmo desvinculá-la de sua função original. No caso dos conjuntos residenciais é viável resignificar os espaços de moradia entendidos como históricos às necessidades atuais de habitação.

O entrelaçamento entre a forma e a função é tema seminal da arquitetura e urbanismo modernos. Os conceitos que levaram à construção do edifício estão nele materializados, e se justificam a partir da função que exercem. Para Beatriz Jaguaribe, os edifícios como a sede do MEC e o Conjunto Residencial Pedregulho perderam sua novidade não apenas pelo desgaste material em si, mas também devido à fragmentação do ethos nacional modernista com o qual foram modelados. Em outras palavras, tornaram-se obsoletos, ruínas modernas (JAGUARIBE, 1998, p.121).

O caso da lavanderia do Conjunto Residencial Pedregulho é emblemático do discurso que se construiu a respeito da obsolescência conceitual que acarreta em degradação física. Projetado e construído entre 1947 e 1962 pelo Departamento de Habitação Popular do antigo Distrito Federal, atual Rio de Janeiro, de autoria de Affonso E. Reidy, o conjunto é emblemático das realizações do movimento moderno no País no campo da habitação popular. Idealizado por Carmen Portinho, diretora do DHP por 14 anos, o Pedregulho integra o projeto de enfrentamento da crise de moradia no Rio de Janeiro por meio da construção de "conjuntos residenciais autônomos", do qual fazem parte os conjuntos de Paquetá e Vila Isabel, de Francisco Bolonha, o Marquês de São Vicente, de Reidy, além do licenciamento de inúmeras casas populares nos subúrbios da cidade.

O plano inicial do Conjunto Residencial Pedregulho previa todos os elementos vitais ao funcionamento de uma unidade de vizinhança: escola, mercado, lavanderia, posto de saúde, blocos residenciais com apartamentos duplex, piscina com vestiários, ginásio, quadra esportiva, grandes jardins com playground, clube e creche. A unidade seria localizada em uma grande quadra, com ruas internas 
acessíveis somente a pedestres e circundada de ruas para carros (NASCIMENTO, 2004).

Um rol de novas atividades possíveis era aberto ao trabalhador, o que muitas vezes causou a estranheza dos novos espaços. O exemplo mais típico e citado desse fenômeno é o uso da lavanderia. Muito se falou sobre seu mau funcionamento e inadequação: ela tornou-se, na mesma medida, um símbolo da sofisticação a que pode chegar um ideário e o ícone do fracasso de uma idéia. Mas a lavanderia coletiva era parte integrante de um projeto de habitação vinculado ao movimento moderno, consubstanciado nas unidades residenciais autônomas. Liberar a mulher trabalhadora das tarefas domésticas, tornando-lhe o cotidiano menos penoso, era objetivo que se queria alcançar com as moradias. Na medida em que os moradores apresentavam resistências ao uso de alguns dos novos equipamentos, a crítica arvorou-se em atestar sua inadequação (CAVALCANTI, 1987).

A questão parece ser mais ampla e deve ser compreendida, neste momento, a partir dos processos históricos. Por certo que os promotores de tais habitações não esperavam que os trabalhadores soubessem utilizar propriamente esses espaços, e menos ainda que o demandassem como direitos (NASCIMENTO, 2004). Os conjuntos residenciais autônomos do Departamento de Habitação Popular, dos Institutos de Aposentadorias e Pensões ou da Fundação da Casa Popular eram planejados e construídos nesses moldes justamente porque, segundo sua ótica, os trabalhadores vinham de condições de moradia condenáveis do ponto de vista moral e higiênico. Da forma planejada, as casas tutelariam os moradores e os transformariam por meio da educação.

Em que medida transformaram ou não, parece ser outra questão, bem como se os conceitos que nortearam a construção dos conjuntos residenciais estão vivos. Este é um dos grandes desafios à preservação dos conjuntos residenciais hoje e do seu entendimento enquanto patrimônio cultural.

Fato é que cotidianamente, os moradores do Pedregulho lançam mão de sua criatividade para dar soluções aos seus problemas de moradia. Desativada a lavanderia desde os anos 1960, e sem qualquer equipamento que a substituísse, os 
moradores privadamente instalam tanques no banheiro e penduram as roupas na janela para secagem. Com a água que escorre pelas fachadas, as esquadrias de madeira vão apodrecendo e são substituídas por alumínio. Logo, o caráter mais peculiar da fachada norte foi brutalmente alterado. Os painéis de cobogós que compõem a fachada sul, fechando o corredor de acesso aos apartamentos, na medida em que quebram são completados por outros tipos existentes no mercado. Mostrando grande sensibilidade para com a obra, os moradores preservam, a seu modo, o caráter da fachada, buscando elementos similares aos originais.

É fundamental, portanto, entender que os processos históricos que levaram às transformações, remodelações e adaptações nos espaços dos conjuntos residenciais devem ser estudados caso a caso, de modo a criar um corpo crítico que permita sua permanência nas nossas cidades como locais legítimos de moradia. É preciso que o legado do movimento moderno, no que tange à problemática da habitação, seja tratado com a mesma ambição com que foi criado (MOREIRA, P., 2001). Os conjuntos residenciais podem ser incluídos na temática da preservação, a partir da sua atualidade como solução à crise de moradia e, sobretudo, do seu local central na história da habitação.

\section{Notas}

(1) A cidade de Brasília, a sede da Bauhaus em Dessau, a cidade de Tel-Aviv, a mansão Tugendhat e a Cidade Universitária de Caracas são dos poucos exemplares do século 20 que integram o patrimônio material tombado pela Unesco.

(2) Estudar as obras do período moderno e promover sua recuperação é tarefa da organização internacional Docomomo - Documentation and Conservation of Buildings, Sites and Neighbourhoods of the Modern Movement, encarregada de discutir seus valores a partir dos pressupostos da Carta de Eindohoven, a qual recomenda: "1. Trazer a público a importância do Movimento Moderno; 2. Identificar e promover o registro das construções do Movimento Moderno o que inclui cadastro, desenhos, fotografias, arquivos e outras formas de documentação; 3. Estimular o desenvolvimento de técnicas e métodos de conservação apropriados, além de difundir tais conhecimentos; 4. Combater a destruição e a desfiguração de obras significativas; 5 . Identificar e atrair fundos para a conservação e documentação; 6. Explorar e desenvolver conhecimentos do Movimento Moderno." (CUNNINGHAM, 1998). Em 1992 o Docomomo-Brasil foi fundado para representar o País na rede internacional. Seu primeiro seminário aconteceu em 1995, na Universidade Federal da Bahia, ao qual se seguiram outros seis seminários, além de alguns encontros regionais. 
(3) Como fala Lauro Cavalcanti, a história da arquitetura brasileira vem sendo "ensinada inúmeras vezes como um interminável mantra".

(4) Francisco Bolonha, Alcides da Rocha Miranda, Carlos Frederico Ferreira e Ernest Mange são exemplos de arquitetos do período moderno que foram objeto de estudos recentes.

(5) Experiência a ressalvar é o Programa Novas Alternativas, promovido pela Prefeitura da Cidade do Rio de Janeiro, que visa restaurar obras de interesse histórico, convertendo-as para habitação de interesse social.

(6) Ver os trabalhos coordenados pelo Prof. Dr. Nabil Bonduki no projeto temático "Habitação Econômica e Arquitetura Moderna (1930-1964)", financiado pela Fapesp, cujos resultados estão reunidos em SAMPAIO; BONDUKI, 1998.

(7) O arquiteto faz essas reflexões a propósito da atuação do Inepac - Instituto Estadual do Patrimônio Cultural do Estado do Rio de Janeiro, do qual foi diretor nos anos 1980.

\section{Referências Bibliográficas}

ATIQUE, Fernando. Memória Moderna - a trajetória do Edifício Esther. São Carlos: Rima, 2003.

ARAVECCHIA, Nilce C. Habitação social no Rio de Janeiro e as contribuições e influências de Carlos Frederico Ferreira e Rubens Porto. Relatório de Pesquisa (Iniciação Científica) - EESC-USP, São Carlos, 1998.

BONDUKI, Nabil. Origens da habitação social no Brasil: arquitetura moderna, Lei do Inquilinato e difusão da casa própria. São Paulo: Estação Liberdade / FAPESP, 1998.

CAMPOFIORITO, Ítalo. O tombamento é um santo remédio. Revista do Brasil, Rio de Janeiro: Secretaria de Estado de Ciência e Cultura / Rioarte, n.1, p.20-29, 1984.

Muda o mundo do patrimônio. Revista do Brasil, Rio de Janeiro: Secretaria de Estado de Ciência e Cultura / Rioarte, n.4, p.32-43, 1985.

CARVALHO, Claudia S. R. de. Preservação da arquitetura moderna: edifícios de escritórios no Rio de Janeiro construídos entre 1930-1960. Tese (Doutorado) - FAU-USP, São Paulo, 2006.

CAVALCANTI, Lauro. Casas para o povo: arquitetura moderna e habitações econômicas. Dissertação (Mestrado) - Ppgas/UFRJ, Rio de Janeiro, 1987.

CHOAY, Françoise. A alegoria do patrimônio. São Paulo: Estação Liberdade / Unesp, 2001.

CHUVA, Márcia. Os arquitetos da memória: construção do patrimônio histórico e artístico nacional no Brasil anos 30 e 40. Tese (Doutorado) -Depto. de História - UFF, Niterói, 1998. 
A eleição do nacional: uma historia materializada em bens simbólicos. Cadernos de Memória Cultural, Rio de Janeiro: Museu da Republica, v.1, n.2, p.92, out/96 - mar/97.

CUNNINGHAM, Allen (Ed.). Modern Movement Heritage. London: E \& FN Spon, 1998.

Diário Oficial do Município do Rio De Janeiro. Poder Executivo, Rio de Janeiro, 12 jul. 2006.

EA.UE. A future for large housing estates: strategies for prefabricated housing estates in central and eastern Europe. Berlim: European Academy of the Urban Environment, 1998.

FONSECA, Maria Cecília Londres. O patrimônio em processo: trajetória da política federal de preservação no Brasil. Rio de Janeiro: UFRJ / Iphan, 1997.

FERRAZ, Marcelo; FANUCCI, Francisco. Bairro Amarelo. Versão Brasileira em Berlim. Revista AU, São Paulo: PINI, n.80, out/nov 1998.

GONÇALVES, José Reginaldo. A retórica da perda: os discursos do patrimônio cultural no Brasil. Rio de Janeiro: UFRJ / Iphan, 2002.

JACOBS, Jane. Morte e vida de grandes cidades. São Paulo: Martins Fontes, 2000.

JAGUARIBE, Beatriz. Fins de século: cidade e cultura no Rio de Janeiro. Rio de Janeiro: Rocco, 1998.

JACQUES, Paola Berenstein. A participação comunitária na cidade contemporânea. Vitruvius, Resenha 106, out. 2004. Disponível em: <www.vitruvius.com.br/resenhas/textos/resenha106.asp> Acesso em: set. 2006.

JENCKS, Charles A. The language of post-modern architecture. Londres: Academy Editions, 1978.

KÜHL, Beatriz Mugayar. Algumas questões relativas ao patrimônio industrial e à sua preservação. Patrimônio, Revista Eletrônica do Iphan. Dossiê Herança Industrial, n.4, mar./abr. 2006. Disponível em: <www.revista.iphan.gov.br/materia.php?id=165> Acesso em: set. 2006.

LUCENA, Adriana. O Iphan e a preservação do patrimônio moderno. São Paulo: PEP / Iphan / Unesco, 2006. Mimeografado.

MAGALHÃES, Aloísio. E Triunfo? A questão dos bens culturais no Brasil. Rio de Janeiro: Nova Fronteira / Fundação Nacional Pró-Memória, 1985.

MELLO, Simone de. Seis conjuntos habitacionais operários em Berlim, exemplares clássicos do modernismo da década de 20, constarão da lista de patrimônio cultural mundial a ser enviada à Unesco. Deutsche Welle, Cultura, 12 jul. 2004. Disponível em: <http://www.dw-world.de/dw/article/0,1564,1264702,00.html> Acesso em: set. 2006 .

MOREIRA, Clarissa. A cidade contemporânea entre a tabula rasa e a preservação: cenários para o porto do Rio de Janeiro. São Paulo: Ed. Unesp, 2004. 
MOREIRA, Pedro. Habitação social e pré-fabricação. A herança socialista em perspectiva. Vitruvius Arquitextos, São Paulo, n.14, jul. $2000 . \quad$ Disponível em: <http://www.vitruvius.com.br/arquitextos/arq014/arq014_03.asp>. Acesso em: set. 2006.

MOTTA, Lia. A apropriação do patrimônio urbano: do estético-estilístico nacional ao consumo visual global. In: ARANTES, Antônio. O espaço da diferença. Campinas: Papirus, 2000. p. 256-287.

NASCIMENTO, Flavia Brito do. Entre a estética e o hábito: o Departamento de Habitação Popular (Rio de Janeiro, 1946-1960). Dissertação (Mestrado) - EESC-USP, São Carlos, 2004.

RADFORD, Gail. Modern housing for America: policy struggles in the New Deal era. Chicago: The University of Chicago Press, 1996.

ROCHA-PEIXOTO, Gustavo. Inepac - Um perfil dos 25 anos de preservação do patrimônio cultural no Estado do Rio de Janeiro. Arquitetura Revista, v.8, n.8, Rio de Janeiro: FAU-UFRJ, 1990.

ROLNIK, Raquel; BALBIM, Renato. Reabilitação de centros urbanos. Brasília: Ministério das Cidades, dez. 2005.

SAMPAIO, Maria Ruth; BONDUKI, Nabil G. (Coord.) Relatório da Pesquisa Habitação Econômica e Arquitetura Moderna no Brasil, encaminhado à Fapesp. São Paulo, 1998. Mimeografado.

SANTOS, Cecília Rodrigues dos; LAGE, Cláudia Freire. Cataguases: patrimônio da modernidade. Vitruvius Arquitextos, São Paulo, n.53, texto especial 273, jan. 2005. Disponível em: <http://www.vitruvius.com.br/arquitextos/arq000/esp273.asp>. Acesso em: set. 2006.

VARGAS, Heliana; CASTILHO, Ana Luisa H. Intervenções em centros urbanos: objetivos, estratégias e resultados. Barueri, SP: Manole, 2006.

* Arquiteta e historiadora. Pós-graduada pela Fundação Bauhaus e doutoranda na FAU-USP. Arquiteta do Iphan, SP. 